\title{
A Response
}

\section{The Articles Editors}

Why are we publishing a set of essays debating the merits of the student-run law review? Similar commentary has appeared before, with apparently little effect on legal scholarship. But these critiques have come largely from outsiders. Adding the perspective of a current board may reveal hidden benefits of the current system and help screen out impracticable reforms. More important, however, we hope that our response will help bring about change, which seems improbable, if not impossible, without some measure of student involvement.

Professor Lindgren's piece reminds us of the potential excesses of student control and suggests further research into student editing practices, coupled with an immediate increase in faculty control. Professor Gordon demonstrates that the current regime has its benefits; unlike Lindgren, she thinks that research should precede any substantial change in law review practices. We agree with Professor Lindgren that useful reform need not await the results of an exhaustive study of the current system. Yet we believe that Lindgren's proposed solution (increased faculty control) is misguided. A better way to respond to Lindgren's concerns, while preserving the educational benefits of student autonomy, would be to institute moderate reforms of the current "market" in law review services. If journals gave professors more candid information about their selection and editing policies, professors could influence the journal market as educated consumers of student services, rather than through direct faculty control.

\section{Selecting ARTicles}

Professor Lindgren makes three principal points regarding articles selection. Law review boards privilege their interests over those of authors or subscribers; they have an elitist preference for credentials over substance; and they distort articles selection through their ignorance and their bias, as future clerks, in favor of federal subjects. Professor Gordon also advocates reform, though she believes the benefits of student control outweigh its vices. 
Obviously, student interests influence what gets published in law reviews. But this influence is probably small. In our experience, we publish what we get, and in more or less the same proportions in which we get it. This is not simply a matter of professors catering to our desires. If professors were not the source of most subject-matter bias, their writing would likely shift to different fields after they received tenure. Yet we have found that submissions from tenured professors continue to concentrate on corporate law, constitutional law, and other federal topics. To the extent that student and faculty preferences diverge, students are more likely to seek out "new" topics—those not already substantially overrepresented in faculty submissions.

Student preferences may not differ much from those of professors, but Professor Lindgren is correct to note that they depart substantially from those of practitioners. We suspect that this is just a matter of law reviews accurately discerning their audience. Law review articles seem to be read primarily by professors, while practitioners and judges seem to rely more heavily on student-written comments. While we might change our audience slightly by publishing more practical articles, increased practitioner interest would, we think, be more than offset by declining faculty readership.

Concerning elitism, it surely happens that editors sometimes select articles on the basis of credentials rather than merit, perhaps due to insecurity about their ability to evaluate merit. We hope that this is rare; certainly many concerned and capable editors know. when they reach the limits of their substantive knowledge, and then seek faculty advice-a service we have found our faculty willing to perform. If editors will not do this, perhaps they should rely on author credentials rather than their own judgments. After all, professors get jobs at elite schools precisely because they are good, original writers-few elite schools base even a part of their tenure decisions on teaching ability.

We agree with Professor Lindgren that the effects of student preferences and elitism on articles selection should be remedied, although we think he exaggerates the extent of the problem. Nevertheless, we cannot fully endorse his two proffered solutions-blind review of submissions and increased faculty involvement.

In theory, we think blind reads could improve the integrity of the selection process. We would not, however, urge their immediate adoption, for blind reads have costs as well as benefits. For a review such as ours, with a current articles staff of two and no 
secretarial staff, their administrative costs would be considerable. At the same time, their benefits are uncertain; acknowledgement notes, textual references to earlier articles by the same author, and the content of footnotes provide numerous clues to the author's identity, and indeed, often state it outright. In addition, even if the process were fully blind, we fear that its effect on publication decisions would not justify the additional costs. The stark truth is that authors submit many articles that do not meet basic criteria of logic and clarity, and somewhat fewer that do. In the end, nearly all the good ones and far too many of the bad are published; eliminating some small element of bias from the selection process might little alter this result. Nonetheless, even if it does not much alter the final mix of articles published, a policy of blind reads would have the benefit of avoiding the appearance of impropriety.

Faculty supervision has still less to recommend it. While we have turned to members of our faculty for subject-matter expertise in making particular publication decisions, assigning final selection decisions to faculty is neither desirable nor feasible. It would be undesirable for students because some measure of authority and responsibility is an important incentive to do better work. Nor would professors benefit from faculty control if, as a result, student edits of their work would be less careful. In addition, dividing responsibility between students and faculty might actually provoke turf wars that would harm all concerned.

Even law review readers outside the legal academy might find faculty control undesirable. It may be reasonable for law reviews to cater primarily to law professors, but they should at least try to make their articles accessible to other readers. Student editing promotes accessibility because, as Professor Gordon notes, student comprehension requires both less technical writing and better documentation of the article's relation to other work in its field.

Not only is faculty oversight undesirable, it is probably unworkable. We doubt that most faculty members are interested in devoting their time to selecting law review articles. If they were, they would start new faculty-run journals, or at least press their services more insistently upon law reviews. Most faculty, however, prefer writing to supervisory work, and it would be hard for law reviews to offer them compensation sufficient to induce them to redirect their efforts. Perhaps student freedom from faculty oversight persists simply because student labor is cheap. 
In short, we agree that the selection process for law review articles is not perfect, and that student editors should try to improve it. Blind reads and increased faculty involvement might help, but neither is a panacea; Professor Gordon is right to suggest further research and reflection before they are adopted.

\section{EDITING ARTICLES}

When it comes to the excesses of student editing, we believe that Professor Lindgren's point is well-taken. It is true that, as Professor Gordon points out, Lindgren overlooks some benefits that student editing offers to editors, readers, and even to authors. Still, we think editors should adopt his rules, because they would safeguard against the perverse incentives of the current system.

The structure and incentives of law review editing virtually guarantee over-editing. In the excessively hierarchical structure of most law reviews, an article may pass through the hands of five or six students, each with an incentive to prove his or her ability to edit. Add to this a tendency to approach an edit like a final exam-the more issues spotted, the better the edit-and it's surprising that pieces are even recognizable when finally published. Thus, even if students are, individually, better editors than Professor Lindgren suggests, light editing should be our goal for systemic reasons.

Our endorsement of a light-editing rule is not, however, unqualified; significant costs may accompany such a rule. First, a number of genuinely insightful articles might never be selected. Some exciting thinkers are, unfortunately, not equally capable writers. Others submit their articles in a state of obvious incompleteness, expecting student editors to fill in the blanks. There are two kinds of writers-those who see the editing process as the students' opportunity to create work for them, and those who see it as their opportunity to assign work to the students-and Professor Lindgren would deny us the opportunity to publish the second kind, whatever benefits their work may offer to readers. Second, accepting the (somewhat elitist) position that, on average, better writers work at better schools, a light editing policy would bias selection in favor of well-credentialed authors. On balance, however, we believe that the benefits of light editing are likely to outweigh its costs.

As in the selection process, we have doubts about the greatly increased faculty role in editing that Lindgren appears to advocate. That practice would impose direct costs on professors (edit- 
ing is even less appealing than articles selection) and would demoralize students. Even if this would produce better legal scholarship (we and Professor Gordon think it would not), it would deprive the students of much of the educational value of law review work. This objection cannot easily be overstated; perhaps the benefits law reviews offer to authors are much less important than their educational role for students.

\section{A MARKET SYSTEM FOR SELECTION AND EDITING}

Whatever the problems of the student-run law review, faculty control is not the answer. Still, no reform is not the answer either. We believe that student editors are capable of initiating some needed changes on their own, without the benefit of further research or faculty guidance. First among these is a sensible editing policy. Light editing, together with advance notice of suggested changes (and the opportunity to veto), has always been our goal. This policy has three advantages. It preserves the author's original voice by preventing rewriting for style alone. Also, treating light editing as the norm allows us to reserve heavy editing for the rare cases in which it is truly needed. Finally, the author's veto gives her ultimate control of her own work, no matter how extensive our suggestions.

More important, students can take the initiative in improving the market for law review services. By disclosing their selection and editing policies, journals can allow authors to exert their influence as consumers, without actually having to run the journals themselves. Eventually, among competitive journals, the more popular policies will attract the more desirable articles, and other journals will be obliged to change to compete.

We have decided to adopt the following disclosure statement; other journals might adopt different statements, varying in content based on their editorial preferences. Ideally, journals would print these statements at the beginning of their reviews, as we have, to make authors better educated consumers of student editing services.

The Editors welcome submissions of manuscripts for publication in the Law Review. Our policies are as follows: 


\section{Selection.}

The Law Review seeks to publish articles making a significant, original contribution to their field. In general, this precludes the publication of case notes or other narrowly focused works. Essays and book reviews will be considered on a very limited basis.

Because our editorial policy affords substantial deference to authors, articles must be both well written and completely argued at the time of submission. Limited resources prevent us from generally filling in the gaps of an otherwise significant article, or substantially correcting its style.

\section{Editing.}

Both the argument of an article and its "voice" should be the creation of the author. Our edits are intended to hone the author's vision, rather than replacing it with our own.

To this end, after completing our substantial round of editing, we send the author a "redlined" copy of the manuscript that shows all changes made. Substantial changes are accompanied by substantive comments or questions. Our changes are meant as reasoned suggestions, not editorial edicts, and we will respect the author's judgment regarding whether the changes should, in the end, be made.

\section{CONCLUSION}

We hope that this exchange encourages law review boards to initiate thoughtful change. In particular, we suggest that Iaw reviews publish their selection criteria for articles and their editing policies. This would both reassure authors and encourage them to send their work to journals whose policies they endorse. 